\title{
In silico Discovery of a New Potent Inhibitor for Sterol 14- alpha Demethylase as a Promising Antifungal Drug against Aspergillus fumigatus Infection
}

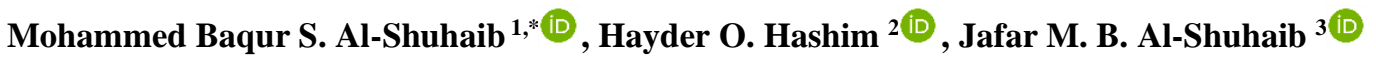 \\ 1 Department of Animal Production, College of Agriculture, Al-Qasim Green University, Al-Qasim, Babil 51001, Iraq; \\ mohammed79@agre.uoqasim.edu.iq (M.B.S.A.S.); \\ 2 Department of Clinical Laboratory Sciences, College of Pharmacy, University of Babylon, Babil 51001, Iraq; \\ phar.hayder.obayes@uobabylon.edu.iq (H.O.H.); \\ 3 Babylon directorate of education, Ministry of education, Babil 51001, Iraq; alshuhaibjmb@gmail.com (J.M.B.A.S.); \\ * Correspondence: mohammed79@agre.uoqasim.edu.iq (M.B.S.A.S.);
}

Scopus Author ID 57196042036

Received: 27.08.2021; Revised: 2.10.2021; Accepted: 5.10.2021; Published: 22.10.2021

\begin{abstract}
Aspergillus fumigatus is a dangerous opportunistic pathogen that causes severe consequences for human beings when its conidia are inhaled. Several inhibitory drugs have recently been suggested to eradicate these fungi by inhibiting the cytochrome P450 sterol 14-alpha demethylase B (CYP51B). These drugs are designed to exhibit high specificity to the heme that is incorporated in the active site of this enzyme. Though effective binding with heme can be achieved, administration of these drugs can be accompanied by variable risks to the user's health. Series of in silico screenings were conducted to find out more eligible drug-like compounds to inhibit CYP51B-heme with fewer side effects on patients. Using stringent ZINCPharmer restrictions, seventeen compounds were found to have efficient binding to the heme group of CYP51B. Their effectiveness against CYP51B was tested using molecular docking, drug-likeness prediction, and molecular dynamics (MD) simulation. One compound (ZINC000015774018 or molecule-8) was found to inhibit the heme group with better drug-likeness than that found in the other sixteen drug-like compounds. MD simulations showed that this ligand introduced stabilized interactions with the targeted protein upon interacting with its heme and amino acid residues. Thus it may be used as a potent antifungal inhibitor against A. fumigatus.
\end{abstract}

Keywords: Aspergillus fumigatus; drug; heme; molecular docking; treatment.

(C) 2021 by the authors. This article is an open-access article distributed under the terms and conditions of the Creative Commons Attribution (CC BY) license (https://creativecommons.org/licenses/by/4.0/).

\section{Introduction}

Aspergillus fumigatus is a pathogenic filamentous fungus that triggers allergic, acute or chronic diseases in both humans and animals. The inhalation of the conidial balls of $A$. fumigatus is the mortal cause among all known pulmonary aspergillosis, which is typically recognized in the form of aspergilloma. Globally, millions of predisposed people acquire pulmonary and allergies to A. fumigatus. A recent estimation suggested over a half million deaths and three million individuals being infected with A. fumigatus per year [1]. Pulmonary aspergillosis is a serious infection and is frequently connected with several harmful symptoms, such as asthma, nasal allergies, and aggravations of tuberculosis. This serious condition of Aspergillus results from the asexual reproduction of the fungus, which generates billions of conidial spores that humans consistently inhale. Additionally, recent researches have 
highlighted the growing incidence of these fungal infections of the cerebrospinal nervous system, with Aspergillus with the primary etiological agents acquired by the respiratory system.

Regardless of the recent suggestions in preventing pulmonary aspergillosis, the prevalence of fungal infections continues to increase, especially in the recent decades in which the ratio of immunocompromised patients has been elevated [2]. In A. fumigatus, a crucial enzyme in the sterol biosynthesis is recognized, called lanosterol 14- $\alpha$-demethylase B (CYP51B). It is involved in removing the lanosterol 14-methyl group to provide the necessary intermediates in ergosterol biosynthesis in the fungal membrane. Thus, the inhibition of CYP51B prevents the transformation of lanosterol to ergosterol [3]. The biosynthesis of ergosterol is mandatory in broad fungal metabolic activities, such as membrane integrity and permeability, cell cycle progression, and cell morphology [4]. Thus, the selective inhibition of this enzyme is extremely prerequisite to ensure a specific therapeutic index [5]. Though several active amino acid residues were recognized in CYP51B, the most important portion in the active site of CYP51B is the heme group. It is widely acknowledged that the heme group is the cornerstone on which CYP51B is largely based in the most metabolic reactions in which this enzyme is involved. Thus, the affinity of any antifungal compound to CYP51B should essentially be determined on binding to the heme group in CYP51B [6]. However, several clinical antifungal agents have been developed with various functions on fungal organisms, such as polyenes, echinocandins, and azoles. Polyenes dispose of ergosterol from cellular membranes; echinocandins can destroy the cell wall, while azole-based compounds can halt the biosynthesis of ergosterol of CYP51B enzyme [7]. Although azole-based drugs are one of the most functional antifungal agents [8], the utilization of each one of these developed drugs still has many constraints related to side effects and pharmacokinetic profile [9]. However, the treatment efficiency with these azole-based ligands remains unacceptably low, and the recovery rate largely depends on how quickly the fungal infection is diagnosed and treated [10]. A recent generation of azole drugs has been developed to inhibit CYP51 in many fungal species [11]. One of the most potent drugs in these recently developed drugs is VT-1598, which has been devised to bind specifically with the heme group of CYP51B [12]. However, it is unknown how this ligand is effective against the emergence of A. fumigatus [13]. Thus, this ligand has not been validated to eradicate A. fumigatus as further comparative in silico and in vitro experiments are required to approve this sort of inhibitory compound. However, the clinical administration of such drugs is not adequate to conquer the increasing fungal infections [14].

For this reason, the present situation makes it entirely inevitable to find out a novel chemical compound possesses better antifungal activity than that found in other suggested drugs. The necessity for such a novel compound with such specific antifungal impact is urgent to increase the possibility of recovery and reduce the side effects of the commonly used antifungal medications. Considering all these data, this study has performed a series of the state-of-the-art in silico computations to find out more appropriate ligands to act as better CYP51B inhibitors. This study aimed to suggest new possible antifungal compounds to act as promising antifungal drugs against the proliferation of A. fumigatus with lower side effects on patients.

\section{Materials and Methods}

A schematic diagram detailing the main tools employed in the study is shown in Figure 1. 


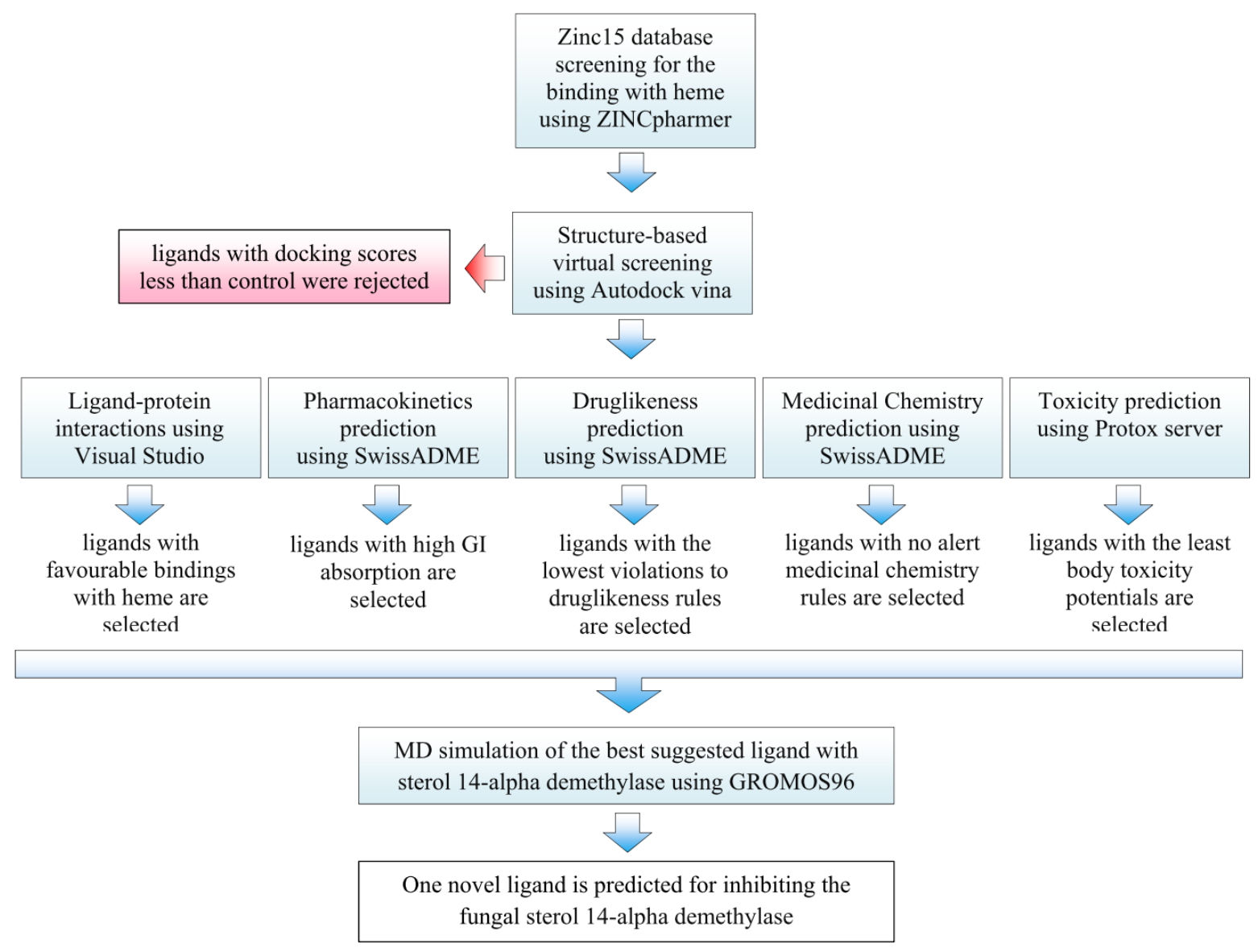

Figure 1. A schematic diagram for the main steps conducted in this study.

\subsection{Generation of pharmacophore models.}

The available X-ray crystallographic structure of the investigated CYP51B protein was deposited in the protein data bank (PDB) in three components; the main protein, heme, and ligand (PDB ID: 5FRB) (http://www.pdb.org). Heme is an intrinsic component of this enzyme, while the ligand VT-1598, the proposed antifungal drug, was attached with its substrate [12]. The state-of-the-art VT-1598 was designed to inhibit the heme group within the CYP51B. Upon retrieving the targeted enzyme, the virtual screening of the heme group was simulated to generate the best pharmacophore models to bind with it. This fungal heme group was used as an input compound in the Zincpharmer web server [15]. The SDF files of the best candidate ligands that ZINCpharmer suggested were retrieved from the ZINC web server [16].

\subsection{Receptor-ligand preparation for molecular docking.}

Concerning receptor preparation, CYP51B was used as a targeted protein receptor for conducting docking experiments. The crystal structure of the fungal CYP51B (5FRB) was obtained from the PDB in a ligand-attached protein complex. The target was prepared by removing its cocrystallized ligand as well as water molecules. Using Discovery Studio Client (Systèmes, Dassault Systèmes Biovia: San Diego, CA, USA), polar hydrogens were added to the protein to get the most appropriate position of side-chain atoms and hydrogen atoms. Concerning ligands preparations, the 3D structures of the retrieved drug-like ligands were subjected to energy minimization and converted to PDBQT format using the graphical user interface of Open Babel, ver. 4.2.0 [17]. 


\subsection{Molecular docking.}

Both protein and ligands were docked using Autodock Vina [18], inbuilt in PyRx software. PyRx is an open-source tool that can be used to screen the ligand potentials to bind with the target site. The virtual screening conditions were the same for all investigated ligands, in which a grid box of $296.74,17.70$, and $11.20 \AA$ for respective $\mathrm{x}, \mathrm{y}$, and $\mathrm{z}$ in the center, and $68.18,62.91$, and $56.07 \AA$ for respective $\mathrm{x}, \mathrm{y}$, and $\mathrm{z}$ in size was set for all cases. After completing docking, all docking drug-like ligands were ranked according to their binding affinity with the CYP51B receptor $(\mathrm{kcal} / \mathrm{mol})$. Each ligand with better docking scores than that found in the incorporated control was considered for downstream analyses.

\subsection{Interactions of the dug-like ligands with critical amino acid residues.}

The atomic interactions between best-docked complexes were conducted. The binding energy of the best binding pose of each docked protein-ligand complex was visualized to unravel the pattern of interactions between the investigated compounds. Using BIOVIA Discovery Studio software, several kinds of ligand-protein interactions were assessed. Further 2D and 3D views of a variety of interactions of best binding poses were analyzed, and their detailed interactions were illustrated. As well, a particular emphasis was made on the possible presence of any type of unfavorable binding in each docked complex.

\subsection{Druglikeness prediction.}

Many possible medicinal compounds could not reach the clinical trials due to their undesirable absorption, distribution, metabolism, and elimination (ADME) parameters [19]. SwissADME webserver was utilized to assess the ADME parameters in the investigated druglike compounds [20]. Ligand structures in SMILES (Simplified molecular-input line-entry system) formats were used as input data in SwissADME to predict several drug-related features, such as pharmacokinetics and drug-likeness following Lipinski's rule of five, Ghose's rule, Veber's rule, Egan's rule, and Muegge's rule. Furthermore, other medicinal chemistry properties were also predicted by SwissADME, such as Pan assay interface compounds (PAINS), Brenk, and Leadlikeness [21]. The potential toxicity of each incorporated ligand was also predicted using the Protox web server [22]. It was also employed to predict the possible hepatoxicity, carcinogenicity, immunotoxicity, mutagenicity, and cytotoxicity of all candidate ligands.

\section{6. $M D$ simulation.}

Downloaded PDB files of the targeted CYP51B, being static and devoid of H-atom; thus, they were optimized and modified to understand dynamic and functional behavior after being conjugated with ligands [1]. Molecular dynamic (MD) simulation of the best proteinligand interactions was conducted to analyze the dynamic stability of the CYP51B upon being docked with both control and best candidate ligands using CHARMM GUI topology-based predictions [23]. The protonation state of the investigated enzyme was achieved at $\mathrm{pH}$ (7.0). To solvate the system, a simple water model was embedded in a cubic box with a minimum distance of $10 \AA$ from the protein surface. Further, an electrically neutral state was achieved by adding chlorine ions and water replacement. Subsequently, the steepest descent energy minimization was carried out until reaching a force tolerance of $1,000 \mathrm{~kJ} / \mathrm{mol}$. Afterward, all 
the system was equilibrated at the temperature of $300.15 \mathrm{~K}$ and 1.0325 bar pressure for $100 \mathrm{ps}$ at fixed number of atoms, pressure, and temperature (NPT ensemble) of MD simulation) [24]. MD runs were performed to predict root mean square deviation (RMSD) and root mean square fluctuation (RMSF), and the trajectories of both simulations were saved in 200 ps intervals. Qtgrace software, ver. 2.6. was utilized to visualize and annotate both simulations.

\section{Results and Discussion}

\subsection{Pharmacophore-based virtual screening.}

This study retrieved the best hit compounds with close features of the reference heme molecule from the ZINC database. The pharmacophore cores with four aromatic and two hydrogen-donor were selected to create the best spatial arrangement of the key features of interaction with the intended molecule [15]. After screening the ZINC database containing more than 250 million compounds using the molecular structure of heme, only seventeen hit compounds were found to exhibit high interaction potentials heme and therefore selected for downstream molecular docking.

\subsection{Molecular docking of ligands against CYP51B.}

A total of seventeen suitable ZINCpharmer-suggested ligands were docked into the CYP51B. The binding energy potential of each protein-ligand complex that emerged from molecular docking was compared with the positive control binding energy value. It was found that fifteen of these ligands possessed higher binding efficiency against CYP51B than in the positive control VT-1598 (Table 1). However, two ligands (ligand no. 17 and 18) were eliminated from further analyses since they exhibited two respective lower binding affinities than that observed in the positive control.

\subsection{Interactions of the ligands with critical residues.}

In addition to the heme group within the CYP51B, the presence of a variable of amino acid residues with hydrogen bonding, polar, Van der Waals, and Pi-Alkyl interaction surrounding the heme was proved variable intensities of connections between the analyzed ligands and CYP51B. The binding conformations of all ligands with docking scores better than those found in the control ligand are shown in the supplementary data (Supplementary file). However, unfavorable bindings were observed in three docked ligand-receptor interactions (ligand no. 4, 6, and 14). These unfavorable bindings would reduce the effectiveness of these ligands and may decrease the stability of the resulting complex. Thus, these four ligands should not be suggested as valid drugs against CYP51B.

\subsection{Druglikeness prediction.}

During the drug design process, the proper pharmacokinetics and bioavailability properties of any suggested drug-like small compounds, such as high GI absorption, intracellular metabolism, and excretion, alongside low toxicity, are essential to confirm their adequacy as a lead compound in the proposed treatment [25]. Membrane permeability, in turn, is an essential feature and especially crucial when managing tiny particles that have intracellular targets since their suitability profoundly relies on their potential to cross cellular membranes [26]. However, the permeability across the cellular membrane for the drug-like 
molecules is assessed by their predicted permeability profile. Interestingly, the prediction proposed only six ligands (ligands no. 4, 8, 10,11, 12, and 13) with high permeability profile out of sixteen investigated ligands, including VT2 control (Table 2).

Table 1. Chemical structures and docking scores of the best-suited ligands to the active site of cytochrome P450 sterol 14-alpha demethylase B of Aspergillus fumigatus. The last two compounds were eliminated from downstream screening due to their lower docking scores than those found in control.

\begin{tabular}{|c|c|c|c|}
\hline No. & Ligand & SMILES & $\begin{array}{c}\text { Docking scores } \\
\text { (Kcal/mol) }\end{array}$ \\
\hline 1. & ZINC000032114523 & $\mathrm{O}=\mathrm{C}(\mathrm{Nc} 1 \mathrm{ccc} 2 \mathrm{oc}(-\mathrm{c} 3 \mathrm{cccc} 4 \mathrm{c}(\mathrm{Cl}) \operatorname{cccc} 34) \mathrm{nc} 2 \mathrm{c} 1) \mathrm{c} 1 \mathrm{ccc}(\mathrm{COc} 2 \mathrm{cccc} 2) \mathrm{cc} 1$ & -14.1 \\
\hline 2. & ZINC000008451394 & $\begin{array}{l}\mathrm{N}=\mathrm{C} 1 / \mathrm{C}(=\mathrm{C} / \mathrm{c} 2 \operatorname{cn}(\mathrm{Cc} 3 \operatorname{ccc} 4 \operatorname{ccc} c 34) \mathrm{c} 3 \operatorname{ccc} c 23) \mathrm{C}(=\mathrm{O}) \mathrm{N}=\mathrm{C} 2 \mathrm{SC}(\mathrm{COc} \\
3 \operatorname{ccc} \mathrm{c} 3)=\mathrm{NN} 12\end{array}$ & -14.0 \\
\hline 3. & ZINC000008493614 & $\begin{array}{l}\mathrm{CCOc} 1 \operatorname{cc}(/ \mathrm{C}=\mathrm{C} 2 / \mathrm{C}(=\mathrm{N}) \mathrm{N} 3 \mathrm{~N}=\mathrm{C}(\mathrm{COc} 4 \operatorname{cccc} 4) \mathrm{SC} 3=\mathrm{NC} 2=\mathrm{O}) \operatorname{ccc} 1 \mathrm{OCc} \\
1 \operatorname{ccc} 2 \operatorname{ccc} 12\end{array}$ & -13.9 \\
\hline 4. & ZINC000016284446 & Cc1cc2nn(-c3ecce4cecce34)nc2cc1NC(=O)c1 ccc(OCc2 $\operatorname{ccccc} 2) \operatorname{cc} 1$ & -13.5 \\
\hline 5. & ZINC000009969135 & $\begin{array}{l}\mathrm{N}=\mathrm{C}(\mathrm{Nc} 1 \mathrm{ccc}(\mathrm{Oc} 2 \mathrm{ccccc} 2) \mathrm{cc} 1) \mathrm{Nc} 1 \mathrm{nc}(\mathrm{CSc} 2 \mathrm{nnnn} 2- \\
\mathrm{c} 2 \mathrm{ccccc} 2) \operatorname{cc}(=\mathrm{O})[\mathrm{nH}] 1\end{array}$ & -13.3 \\
\hline 6. & ZINC000027472327 & $\begin{array}{l}\text { Oc1 } 1 \mathrm{ccc} 2 \mathrm{ccccc} 2 \mathrm{c} 1 / \mathrm{C}=\mathrm{N} / \mathrm{c} 1 \mathrm{ccc}(\mathrm{Nc} 2 \mathrm{ccc}(/ \mathrm{N}=\mathrm{C} / \mathrm{c} 3 \mathrm{c}(\mathrm{O}) \operatorname{ccc} 4 \mathrm{ccccc} 34) \mathrm{cc} 2) \\
\mathrm{cc} 1\end{array}$ & -13.2 \\
\hline 7. & ZINC000033809114 & $\begin{array}{l}\mathrm{O}=\mathrm{C}(\mathrm{Nc} 1 \mathrm{ccc}(/ \mathrm{N}=\mathrm{N} \mid \mathrm{c} 2 \mathrm{ccccc} 2) \mathrm{cc} 1) \mathrm{c} 1 \mathrm{ccc} 2 \mathrm{nc}(-\mathrm{c} 3 \operatorname{ccccc} 3) \mathrm{c}(- \\
\mathrm{c} 3 \mathrm{cccc} 3) \mathrm{nc} 2 \mathrm{c} 1\end{array}$ & -13.2 \\
\hline 8. & ZINC000015774018 & $\begin{array}{l}\mathrm{O}[\mathrm{C} @ \mathrm{H}](\mathrm{c} 1 \mathrm{ccccc} 1) \mathrm{c} 1 \mathrm{ccc}(\mathrm{CCCc} 2 \mathrm{ccc}([\mathrm{C} @ @ \mathrm{H}](\mathrm{c} 3 \mathrm{ccccc} 3) \mathrm{n} 3 \mathrm{cnnc} 3) \mathrm{cc} \\
\text { 2)cc1 }\end{array}$ & -13.2 \\
\hline 9. & ZINC000004016627 & $\begin{array}{l}\mathrm{O}=\mathrm{S}(=\mathrm{O})(\mathrm{Oc} 1 \mathrm{ccccc} 1) \mathrm{c} 1 \mathrm{cc}(- \\
\mathrm{n} 2 \mathrm{nc} 3 \operatorname{ccc} 4 \mathrm{c}(\mathrm{S}(=\mathrm{O})(=\mathrm{O}) \mathrm{Oc} 5 \operatorname{ccccc} 5) \operatorname{cccc} 4 \mathrm{c} 3 \mathrm{n} 2) \operatorname{ccc} 1 / \mathrm{C}=\mathrm{C} / \mathrm{c} 1 \mathrm{ccccc} 1\end{array}$ & -13.1 \\
\hline 10. & ZINC000015774047 & $\begin{array}{l}\mathrm{O}[\mathrm{C} @ @ \mathrm{H}](\mathrm{c} 1 \mathrm{ccccc} 1) \mathrm{c} 1 \mathrm{ccc}(\mathrm{CCC} 2 \mathrm{ccc}([\mathrm{C} @ @ \mathrm{H}](\mathrm{c} 3 \mathrm{ccccc} 3) \mathrm{n} 3 \mathrm{cncn} 3) \\
\mathrm{cc} 2) \mathrm{cc} 1\end{array}$ & -13.0 \\
\hline 11. & ZINC000015774049 & $\begin{array}{l}\mathrm{O}[\mathrm{C} @ \mathrm{H}](\mathrm{c} 1 \mathrm{ccccc} 1) \mathrm{c} 1 \mathrm{ccc}(\mathrm{CCC} 2 \mathrm{ccc}([\mathrm{C} @ @ \mathrm{H}](\mathrm{c} 3 \operatorname{ccccc} 3) \mathrm{n} 3 \mathrm{cncn} 3) \mathrm{cc} \\
\text { 2)cc1 }\end{array}$ & -13.0 \\
\hline 12. & ZINC000015774024 & $\begin{array}{l}\text { c1cce([C@H](c2ccc(CCCc3ccc([C@@H](c4ccccc4)n4cncn4)cc3)cc2 } \\
\text { )n2cnnc2)cc1 }\end{array}$ & -12.9 \\
\hline 13. & ZINC000015774016 & $\begin{array}{l}\mathrm{O}[\mathrm{C} @ @ \mathrm{H}](\mathrm{c} 1 \mathrm{ccccc} 1) \mathrm{c} 1 \mathrm{ccc}(\mathrm{CCC} 2 \mathrm{ccc}([\mathrm{C} @ @ \mathrm{H}](\mathrm{c} 3 \mathrm{ccccc} 3) \mathrm{n} 3 \mathrm{cnnc} 3) \\
\mathrm{cc} 2) \mathrm{cc} 1\end{array}$ & -12.8 \\
\hline 14. & ZINC000040645852 & $\begin{array}{l}\mathrm{O}=[\mathrm{N}+]([\mathrm{O}- \\
]) \mathrm{c} 1 \mathrm{c}(\mathrm{Nc} 2 \mathrm{ccc}(/ \mathrm{N}=\mathrm{N} / \mathrm{c} 3 \operatorname{ccccc} 3) \mathrm{cc} 2) \mathrm{ncnc} 1 \mathrm{Nc} 1 \mathrm{ccc}(/ \mathrm{N}=\mathrm{N} / \mathrm{c} 2 \operatorname{ccccc} 2) \mathrm{cc} 1\end{array}$ & -12.4 \\
\hline 15. & ZINC000002094098 & COc1 $1 \mathrm{cc}(\mathrm{CNc} 2 \mathrm{ccc}(\mathrm{Oc} 3 \operatorname{ccc} c 3) \mathrm{cc} 2) \mathrm{cc}(\mathrm{Cl}) \mathrm{c} 1 \mathrm{OCc} 1 \mathrm{cccc} 2 \mathrm{cccc} 12$ & -12.0 \\
\hline 16. & VT2 (control) & $\begin{array}{l}\mathrm{C} 1=\mathrm{CC}(=\mathrm{CC}=\mathrm{C} 1 \mathrm{COC} 2=\mathrm{CC}=\mathrm{C}(\mathrm{C}=\mathrm{C} 2) \mathrm{C} \# \mathrm{CC} 3=\mathrm{CN}=\mathrm{C}(\mathrm{C}=\mathrm{C} 3) \mathrm{C}([\mathrm{C} @] \\
(\mathrm{CN} 4 \mathrm{C}=\mathrm{NN}=\mathrm{N} 4)(\mathrm{C} 5=\mathrm{C}(\mathrm{C}=\mathrm{C}(\mathrm{C}=\mathrm{C} 5) \mathrm{F}) \mathrm{F}) \mathrm{O})(\mathrm{F}) \mathrm{F}) \mathrm{C} \# \mathrm{~N}\end{array}$ & -11.5 \\
\hline 17. & ZINC000095101010 & $\begin{array}{l}\mathrm{O}=\mathrm{S}(=\mathrm{O})(\mathrm{O}) \mathrm{c} 1 \mathrm{ccc} 2 \mathrm{c}(/ \mathrm{N}=\mathrm{N} / \mathrm{c} 3 \operatorname{ccc}(/ \mathrm{N}=\mathrm{N} / \mathrm{c} 4 \mathrm{ccc}(\mathrm{Nc} 5 \mathrm{ccccc} 5) \mathrm{cc} 4 \mathrm{Nc} 4 \mathrm{ccc} \\
\mathrm{cc} 4) \mathrm{c} 4 \mathrm{ccccc} 34) \operatorname{cc}(\mathrm{S}(=\mathrm{O})(=\mathrm{O}) \mathrm{O}) \operatorname{cc} 2 \mathrm{c} 1\end{array}$ & -10.7 \\
\hline 18. & ZINC000015774028 & $\begin{array}{l}\text { c1ccc([C@@H](c2 } \operatorname{ccc}(\mathrm{CCCc} 3 \operatorname{ccc}([\mathrm{C} @ @ \mathrm{H}](\mathrm{c} 4 \mathrm{ccccc} 4) \mathrm{n} 4 \mathrm{cnnc} 4) \mathrm{cc} 3) \mathrm{c} \\
\mathrm{c} 2) \mathrm{n} 2 \mathrm{cncn} 2) \mathrm{cc} 1\end{array}$ & -9.3 \\
\hline
\end{tabular}

Through the SwissADME server, Lipinski, Ghose, Veber, Egan, and Muegge rules were used as filters to provide a sufficient rationale for the grouping of each compound as a drug or nondrug. Any virtually screened molecule should pass these filters before it is suggested for oral administration [27]. More reduction in drug-likeness of a lead compound may happen due to more violation of this compound by any one of these filters [28]. It was found that molecule- 8 was the most submissive for drug-likeness filtrations, while the other applied molecule exerted variable eligibility for these rules. More validations for the obvious eligibility of molecule- 8 over the other molecules were obtained from the SwissADME-boiled egg chart. The physicochemical properties and their consequent oral bioavailability of the investigated ligands were plotted as a BOILED-Egg graph (Figure 2). The yellow (egg-yolk) and white (egg-white) areas represent the optimal and suboptimal ranges physiochemical properties, respectively [29]. 


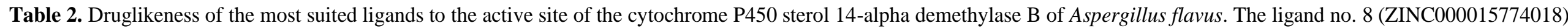

\begin{tabular}{|c|c|c|c|c|c|c|c|c|c|c|c|c|c|c|c|c|}
\hline \multirow[t]{2}{*}{ No. } & \multirow[t]{2}{*}{ Ligand } & \multirow{2}{*}{$\begin{array}{l}\begin{array}{l}\text { Visual } \\
\text { studio }\end{array} \\
\begin{array}{l}\text { Unfavour- } \\
\text { able } \\
\text { bindings }\end{array}\end{array}$} & \multirow{2}{*}{$\begin{array}{l}\begin{array}{l}\text { Pharmaco } \\
\text { kinetics }\end{array} \\
\text { GI } \\
\text { absorption }\end{array}$} & \multicolumn{5}{|c|}{ Druglikeness } & \multicolumn{3}{|c|}{ Medicinal chemistry } & \multicolumn{5}{|l|}{ Toxicity } \\
\hline & & & & $\begin{array}{l}\text { Lipinski } \\
\text { rules } \\
\text { violations }\end{array}$ & $\begin{array}{l}\text { Ghose } \\
\text { rules } \\
\text { violations }\end{array}$ & $\begin{array}{l}\text { Veber } \\
\text { rules } \\
\text { violations }\end{array}$ & $\begin{array}{l}\text { Egan rules } \\
\text { violations }\end{array}$ & $\begin{array}{l}\text { Muegge } \\
\text { rules } \\
\text { violations }\end{array}$ & PAINS & Brenk & Leadlikeness & $\begin{array}{l}\text { Hepatox- } \\
\text { icity }\end{array}$ & $\begin{array}{l}\text { Carcinog- } \\
\text { enicity }\end{array}$ & $\begin{array}{l}\text { Immunot- } \\
\text { oxicity }\end{array}$ & $\begin{array}{l}\text { Mutag- } \\
\text { enicity }\end{array}$ & Cytotoxicity \\
\hline 1. & ZINC000032114523 & None & Low & 2 violations & 3 violations & Yes & 1 violation & 1 violation & 0 alert & 0 alert & 2 violations & Active & Active & Inactive & Inactive & Inactive \\
\hline 2. & ZINC000008451394 & None & Low & 2 violations & 2 violations & Yes & Yes & 1 violation & 0 alert & 2 alerts & 2 violations & Active & Inactive & Active & Inactive & Inactive \\
\hline 3. & ZINC000008493614 & None & Low & 1 violation & 2 violations & Yes & Yes & 1 violation & 0 alert & 2 alerts & 3 violations & Active & Inactive & Active & Active & Inactive \\
\hline 4. & ZINC000016284446 & One found & High & 1 violation & 3 violations & Yes & 1 violation & 1 violation & 0 alert & 0 alert & 2 violations & Inactive & Active & Inactive & Active & Inactive \\
\hline 5. & ZINC000009969135 & None & Low & 1 violation & 2 violations & 1 violation & 1 violation & 1 violation & 0 alert & 2 alerts & 3 violations & Inactive & Active & Inactive & Active & Inactive \\
\hline 6. & ZINC000027472327 & One found & Low & 1 violation & 3 violations & \begin{tabular}{l|l} 
Yes \\
\end{tabular} & 1 violation & 1 violation & 0 alert & 1 alert & 2 violations & Active & Inactive & Active & Inactive & Inactive \\
\hline 7. & ZINC000033809114 & None & Low & 1 violation & 3 violations & Yes & 1 violation & 1 violation & 1 alert & 1 alert & 2 violations & Active & Active & Inactive & Inactive & Inactive \\
\hline 8. & ZINC000015774018 & None & High & 1 violation & 2 violations & Yes & Yes & 1 violation & 0 alert & 0 alert & 3 violations & Inactive & Inactive & Inactive & Inactive & Inactive \\
\hline 9. & ZINC000004016627 & None & Low & 2 violations & 4 violations & Yes & 2 violations & 2 violations & 0 alert & 2 alerts & 3 violations & Inactive & Inactive & Active & Inactive & Inactive \\
\hline 10. & ZINC000015774047 & None & High & 1 violation & 2 violations & Yes & Yes & 1 violation & 0 alert & 0 alert & 3 violations & Active & Inactive & Active & Inactive & Inactive \\
\hline 11. & ZINC000015774049 & None & High & 1 violation & 2 violations & Yes & Yes & 1 violation & 0 alert & 0 alert & 3 violations & Inactive & Active & Inactive & Inactive & Inactive \\
\hline 12. & ZINC000015774024 & None & High & 2 violations & 3 violations & Yes & 1 violation & 1 violation & 0 alert & 0 alert & 3 violations & Inactive & Inactive & Inactive & Active & Inactive \\
\hline 13. & ZINC000015774016 & None & High & 1 violation & 2 violations & Yes & Yes & 1 violation & 0 alert & 0 alert & 3 violations & Active & Inactive & Active & Inactive & Inactive \\
\hline 14. & ZINC000040645852 & Two found & Low & 3 violations & 3 violations & 1 violation & 2 violations & 1 violation & 1 alert & 3 alerts & 3 violations & Active & Active & Inactive & Active & Inactive \\
\hline 15. & ZINC000002094098 & None & Low & 1 violation & 3 violations & Yes & 1 violation & 1 violation & 0 alert & 0 alert & 3 violations & Inactive & Inactive & Active & Active & Active \\
\hline 16. & VT2 (control) & None & Low & 2 violations & 3 violations & Yes & 1 violation & 1 violation & 0 alert & 1 alert & 3 violations & Active & Inactive & Active & Inactive & Inactive \\
\hline
\end{tabular}

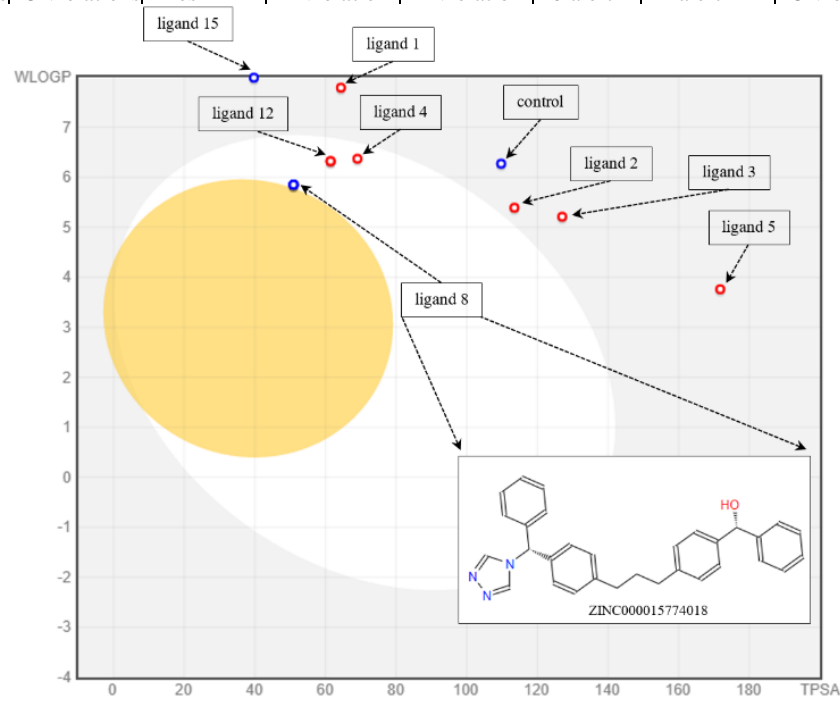

Figure 2. Boiled-egg graph of the most eligible drug among the investigated ligands against Aspergillus fumigatus sterol 14-alpha demethylase. Five ligands (numbered 6, 7, 9, 10, 11, 13, and 14) were not represented in this chart since they were out of range.

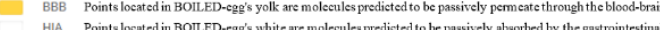

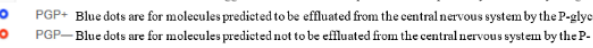


Very promising CYP51B inhibitory activity was observed from molecule- 8 because it occupied the most proximal position to the range of the yellow area, while both ligands no. 4 and no. 12 were positioned further in the white area. At the same time, other tested ligands (no. 1, 2, 3, 4, 5, and control) were positioned outside both areas. However, other ligands (no. 6, 7, $9,10,11,13$, and 14) were not represented in this chart since they were entirely out of the proposed ranges of the boiled egg plot. In addition to drug-likeness properties, further filtrations were conducted for heme-binding ligands using medicinal chemistry properties and potential toxicity predictions. As in the case of pharmacokinetics and drug-likeness, molecule8 exhibited the most medicinal chemistry friendliness and the least predicted toxicity consequences among all other tested compounds. However, variable degrees of violations were witnessed for other suggested ligands. Thus, it can be stated that molecule- 8 was the lead molecule that proved to possess the best-tested properties other than those found in other suggested ligands, including the positive control.

\subsection{MD simulation.}

Enzymes are macromolecules that are not static, so their motion induces variable structural fluctuation, which may influence their corresponding functional stability [30-33]. Interestingly, MD simulation is the only method that can analyze the structural-functional actions of enzymes in different conditions. In this study, two independent simulations were conducted to evaluate the structural fluctuation and functional stability of the VT-1598CYP51B complex and the selected molecule-8-CYP51B complex.

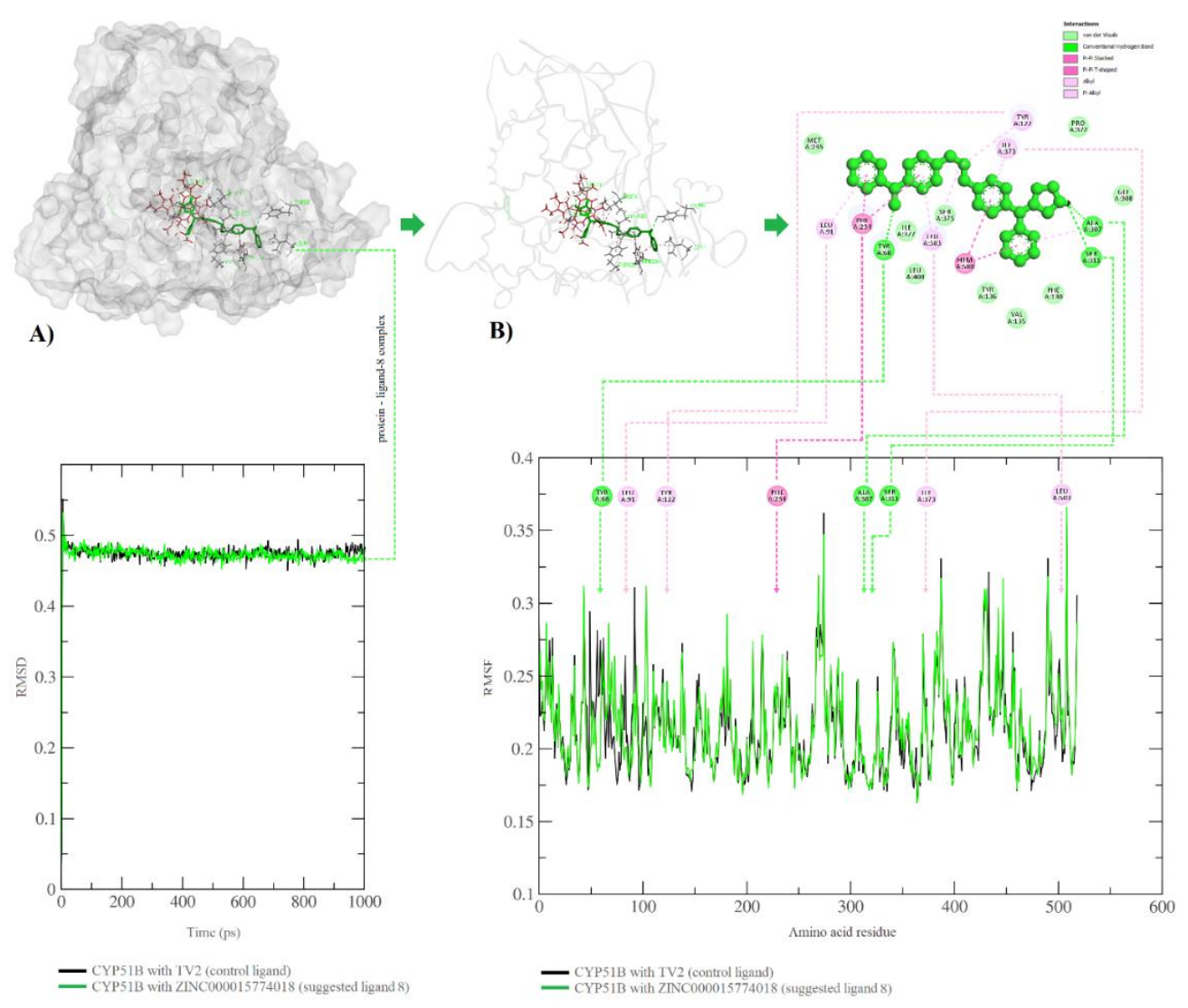

Figure 3. Comparative molecular dynamic (MD) simulation of both fungal cytochrome P450 sterol 14-alpha demethylase B complexed with the ligand 8 (green color) and VT-1598 control (black color). A) Root-meansquare deviation (RMSD) in $\mathrm{A}^{\circ}$ plotted against 1000 ps simulation time. B) Root-mean-square fluctuation (RMSF) in $\mathrm{A}^{\circ}$ plotted against amino acid residues. All amino acid residues involved in direct interactions with ligand 8 were highlighted above the RMSF plot. 
The results of the RMSD plot indicated that both CYP51B complexed with VT-1598 and lead molecule- 8 were quite consistent, suggesting the stability of both complexes in the entire time of simulation (Figure 3A). Likewise, the general behavior of CYP51B was observed to be rather stable in the entire MD simulation period of $1000 \mathrm{ps}$ in both simulated complexes. This observation entailed a comparable validity of both molecule- 8 and VT2 control in the binding with the targeted heme moiety in considerable stability. Another layer of confirmation was provided by calculating RMSF for molecule-8 - CYP51B interactions. The plotting of amino acid residues that involved in making direct interactions with molecule- 8 was conducted. RMSF plot showed that all the visual studio observed ligand-protein interactions (Tyr68, Leu91, Tyr122, Phe234, Ala307, Ser311, Ile373, and Leu503) were positioned in nonfluctuated areas (Figure 3B). Thus, both RMSD and RMSF values were similar for both complexes, which suggested the validity of the lead molecule- 8 alongside the positive control. Overall, MD simulation results discovered that the lead molecule- 8 has considerable binding stability against the soluble CYP51B enzyme.

\subsection{Discussion.}

CYP51B plays a key role in the A. fumigatus cell wall synthesis through its heme group. The heme group is an intrinsic component of the CYP51B, which is encrypted in a crucial position within the active site of this protein. Thus inactivating this group would inhibit this protein and prevent it from performing its scheduled role in fungal cell wall synthesis. VT1598, a specific drug, has recently been developed to inhibit CYP51B by binding to the heme group [12]. However, this study showed that this recently suggested drug violated several druglikeness and pharmacokinetic properties. Therefore, this study has suggested an alternative antifungal agent with more eligible physiochemical properties and better oral bioavailability.

The main approach of this study was taken place by conducting many computations to set out more eligible antifungal drugs having better pharmacokinetics and bioavailability properties. Thus, the utilization of these compounds offers superiority over the few suggested medicines with no or minimal side effects. The vast importance of variable computational tools was employed to screen a wide range of compounds to reveal their potential to be sued as inhibitors against the fungal CYP51B. Using the ZINCpharmer, more than 250 million chemical compounds were evaluated to find the most suitable group to bind with the heme moiety of the fungal CYP51B. Only seventeen compounds were retrieved from ZINCpharmer and subjected to a series of downstream computations to evaluate their drug-like potentials. Upon validation, the most appropriate drug-like capacity was confirmed in the case of molecule-8. Thus, the structure of this chemical was virtually screened against CYP51B within its well-known heme-binding site. However, based on suitable binding affinity and drug-like properties, molecule- 8 was selected for both Visual Studio and MD simulation analyses. Visual Studio has been established as a valuable computational tool to recognize the most eligible molecule against any target [34]. Visual Studio showed that molecule-8 is one of the compounds enjoyed with powerful binding affinities against CYP51B due to the presence of variable types of ligand-protein binding interactions. To support this observation, 2D interaction analysis has suggested the presence of remarkable interactions of the lead molecule8 with the CYP51B. In addition to the observed direct interaction with the targeted heme, the lead molecule-8 was also involved in several types of interactions with several amino acid residues surrounding the heme group, including hydrogen bond, Van der Waals interaction, PiPi shaped, Pi-Pi stacked, and Pi-alkyl. What increased the importance of such interactions is 
the presence of several hydrogen bonding, alkyl, and bi-alkyl interactions of molecule- 8 with Tyr68, Leu91, Tyr122, Phe234, Ala307, Ser311, Ile373, and Leu503. As it was shown by the ConSurf tool [35], half of these residues (Tyr68, Leu91, Tyr122, and Ser311) were positioned in extremely high conserved regions, while the other half (Phe234, Ala307, Ile373, and Leu503) were positioned in highly conserved regions. One of these residues that participated in the direct interaction with molecule-8 is Tyr122, which was involved in inducing dramatic topological changes in CYP51B when interacting with several triazole-based drugs [36]. In addition to the favorable binding with the heme and other amino acid residues, the lead ligand8 was characterized with better pharmacokinetic features than that found in the control. The Protox-based toxicity predictions found that molecule- 8 was not toxic, while the control was found to have potential carcinogenic effects. Moreover, the BOILED-egg test showed that molecule- 8 has the best drug-like features compared to all other investigated drug-like compounds, including control. However, both ligand-8 and control showed comparable results in MD simulations. In the RMSF plot, many arbitrary fluctuations were observed, but no conformational shifting was seen in the positions occupied by residues involved in direct ligand binding interactions. The values of RMSD suggested that the binding of both complexes has been stabilized without any conformational shift. These data have cumulatively suggested that molecule- 8 has a noticeable binding efficiency with heme and several amino acid residues and may be used as putative inhibitors against the CYP51B. Thus, it can be stated that in addition to the biological importance of molecule-8 interactions with CYP51B, sufficient biological stability was ensured in this complex. This observation entailed the ability of the molecule- 8 to ensure solid binding with heme, crucial interactions with amino acid residues, and sufficient dynamic stability of the consequent complex upon formation.

\section{Conclusions}

This study found one compound (molecule-8 or ZINC000015774018) with a stable binding capacity against CYP51B and a high-quality pharmacokinetic profile. Therefore, it is concluded that this compound can be employed as a potent antifungal drug against the most invasive respiratory infections represented by A. fumigatus. The therapeutic potentials of this new chemical compound and may be further expanded for in vitro validation against the infectivity of A. fumigatus in the nearest future.

\section{Funding}

The authors declared that this research received no external funding from any agency or institution.

\section{Acknowledgments}

The authors are thankful to Dr. Zahid Kamalaldeen, college of agriculture, Al-Qasim Green University, for his continuous and kind support.

\section{Conflicts of Interest}

The authors declare no conflict of interest. 


\section{References}

1. Shukla, P.; Deswal, D.; Azad, C.S.; Narula, A.K. Novel nucleosides as potential inhibitors of fungal lanosterol 14a-demethylase: an in vitro and in silico study. Future Medicinal Chemistry 2019, 11, 2663-86, https://doi.org/10.4155/fmc-2019-0014.

2. Pappas, P.G.; Kauffman, C.A.; Andes, D.R.; Clancy, C.J.; Marr, K.A.; Ostrosky-Zeichner, L.; Reboli, A.C.; Schuster, M.G.; Vazquez, J.A.; Walsh, T.J.; Zaoutis, T.E. Clinical practice guideline for the management of candidiasis: 2016 update by the Infectious Diseases Society of America. Clinical Infectious Diseases 2016, 62, e1-e50, https://doi.org/10.1093/cid/civ933.

3. Rauseo, A.M.; Coler-Reilly, A.; Larson, L., Spec, A. Hope on the horizon: novel fungal treatments in development. InOpen forum infectious diseases, ofaa01. US: Oxford University Press 2020, 7, https://doi.org/10.1093/ofid/ofaa016.

4. Rodrigues, M.L. The multifunctional fungal ergosterol. MBio 2018, 9, e01755-18, https://doi.org/10.1128/mBio.01755-18.

5. Lepesheva, G.I.; Friggeri, L.; Waterman, M.R. CYP51 as drug targets for fungi and protozoan parasites: past, present and future. Parasitology 2018, 145, 1820-36, https://doi.org/10.1017/S0031182018000562.

6. Can, N.Ö.; Acar Çevik, U.; Sağlık, B.N.; Levent, S.; Korkut, B.; Özkay, Y.; Kaplancıklı, Z.A.; Koparal, A.S. Synthesis, molecular docking studies, and antifungal activity evaluation of new benzimidazole-triazoles as potential lanosterol 14 $\alpha$-demethylase inhibitors. Journal of Chemistry 2017, 2017, https://doi.org/10.1155/2017/9387102.

7. Lepesheva, G.I.; Waterman, M.R. Sterol 14 $\alpha$-demethylase cytochrome P450 (CYP51), a P450 in all biological kingdoms. Biochimica et Biophysica Acta (BBA)-General subjects 2007, 1770, 467-77, https://doi.org/10.1016/j.bbagen.2006.07.018.

8. Denning, D.W.; Bromley, M.J. How to bolster the antifungal pipeline. Science 2015, 347, 1414-6, https://doi.org/10.1126/science.aaa6097.

9. Wilson, D.T.; Dimondi, V.P.; Johnson, S.W.; Jones, T.M.; Drew, R.H. Role of isavuconazole in the treatment of invasive fungal infections. Therapeutics and Clinical Risk Management 2016, 12, 1197-1206, https://doi.org/10.2147/TCRM.S90335.

10. Brown, G.D.; Denning, D.W.; Gow, N.A.; Levitz, S.M.; Netea, M.G.; White, T.C. Hidden killers: human fungal infections. Science translational medicine 2012, 4, 165rv13, https://doi.org/10.1126/scitranslmed.3004404.

11. Zhang, J.; Li, L.; Lv, Q.; Yan, L.; Wang, Y.; Jiang, Y. The fungal CYP51s: their functions, structures, related drug resistance, and inhibitors. Frontiers in Microbiology 2019, 10, https://doi.org/10.3389/fmicb.2019.00691.

12. Hargrove, T.Y.; Garvey, E.P.; Hoekstra, W.J.; Yates, C.M.; Wawrzak, Z.; Rachakonda, G.; Villalta, F.; Lepesheva, G.I. Crystal structure of the new investigational drug candidate VT-1598 in complex with Aspergillus fumigatus sterol 14 $\alpha$-demethylase provides insights into its broad-spectrum antifungal activity. Antimicrobial agents and chemotherapy 2017, 61, e00570-17, https://doi.org/10.1128/AAC.0057017.

13. Wiederhold, N.P. The antifungal arsenal: alternative drugs and future targets. International Journal of Antimicrobial Agents 2018, 51, 333-9, https://doi.org/10.1016/j.ijantimicag.2017.09.002.

14. Shafiei, M.; Peyton, L.; Hashemzadeh, M.; Foroumadi, A. History of the development of antifungal azoles: A review on structures, SAR, and mechanism of action. Bioorganic Chemistry 2020, 104, https://doi.org/10.1016/j.bioorg.2020.104240.

15. Koes, D.R.; Camacho, C.J. ZINCPharmer: pharmacophore search of the ZINC database. Nucleic acids research 2012, 40, W409-14, https://doi.org/10.1093/nar/gks378.

16. Sterling, T.; Irwin, J.J. ZINC 15-ligand discovery for everyone. Journal of Chemical Information and Modeling 2015, 55, 2324-37, https://doi.org/10.1021/acs.jcim.5b00559.

17. O'Boyle, N.M.; Banck, M.; James, C.A.; Morley, C. Open Babel: An open chemical toolbox. Journal of Cheminformatics 2011, 3, 1-14, https://doi.org/10.1186/1758-2946-3-33.

18. Trott, O.; Olson, A.J. AutoDock Vina: improving the speed and accuracy of docking with a new scoring function, efficient optimization, and multithreading. Journal of Computational Chemistry 2010, 31, 455-61, https://doi.org/10.1002/jcc.21334.

19. Abdelli, I.; Hassani, F.; Bekkel Brikci, S.; Ghalem, S. In silico study the inhibition of angiotensin converting enzyme 2 receptor of COVID-19 by Ammoides verticillata components harvested from Western Algeria. Journal of Biomolecular Structure and Dynamics 2021, 39, 3263-3276, https://doi.org/10.1080/07391102.2020.1763199.

20. Daina, A.; Michielin, O.; Zoete, V. SwissADME: a free web tool to evaluate pharmacokinetics, drug-likeness and medicinal chemistry friendliness of small molecules. Scientific reports 2017, 7, https://doi.org/10.1038/srep42717.

21. Baell, J.B.; Nissink, J.W. Seven Year Itch: Pan-Assay Interference Compounds (PAINS) in 2017 - Utility and Limitations. ACS chemical biology 2018, 13, 36-44, https://doi.org/10.1021/acschembio.7b00903. 
22. Banerjee, P.; Eckert, A.O.; Schrey, A.K.; Preissner, R. ProTox-II: a webserver for the prediction of toxicity of chemicals. Nucleic acids research 2018, 46, W257-63, https://doi.org/10.1093/nar/gky318.

23. Lee, J.; Hitzenberger, M.; Rieger, M.; Kern, N.R.; Zacharias, M.; Im, W. CHARMM-GUI supports the Amber force fields. The Journal of Chemical Physics 2020, 153, https://doi.org/10.1063/5.0012280.

24. Raj, U., Kumar, H., Varadwaj, P.K. Molecular docking and dynamics simulation study of flavonoids as BET bromodomain inhibitors. Journal of Biomolecular Structure and Dynamics 2017, 35, 2351-2362, https://doi.org/10.1080/07391102.2016.1217276.

25. Jagadeb, M.; Rath, S.N.; Sonawane A. In silico discovery of potential drug molecules to improve the treatment of isoniazid-resistant Mycobacterium tuberculosis. Journal of Biomolecular Structure and Dynamics 2019, 37, 3388-3398, https://doi.org/10.1080/07391102.2018.1515116.

26. Bennion, B.J.; Be, N.A.; McNerney, M.W.; Lao, V.; Carlson, E.M.; Valdez, C.A.; Malfatti, M.A.; Enright, H.A.; Nguyen, T.H.; Lightstone, F.C.; Carpenter, T.S. Predicting a drug's membrane permeability: A computational model validated with in vitro permeability assay data. The journal of physical chemistry B 2017, 121, 5228-5237, https://doi.org/10.1021/acs.jpcb.7b02914.

27. Pathania, S.; Singh, P.K. Analyzing FDA-approved drugs for compliance of pharmacokinetic principles: should there be a critical screening parameter in drug designing protocols?, Expert Opinion on Drug Metabolism \& Toxicology 2021, 4, 351-354, https://doi.org/10.1080/17425255.2021.1865309.

28. Rath, S.N.; Jena, L.; Bhuyan, R.; Mahanandia, N.C.; Patri, M. In silico discovery and evaluation of phytochemicals binding mechanism against human catechol-O-methyltransferase as a putative bioenhancer of L-DOPA therapy in Parkinson disease. Genomics \& Informatics 2021, 19, https://doi.org/10.5808/gi.20061.

29. Daina, A.; Zoete, V. A boiled-egg to predict gastrointestinal absorption and brain penetration of small molecules. ChemMedChem 2016, 11, https://doi.org/10.1002/cmdc.201600182.

30. Albakri, A.H.; Al-Shuhaib, M.B.S.; Alwan, S.L.; AbdulAzeez, S.; Borgio, J.F. Deleterious missense variants in the aflatoxin biosynthesis genes explain the low toxicity of Aspergillus flavus from infected rice. Microbial Pathogenesis 2020, 152, https://doi.org/10.1016/j.micpath.2020.104605.

31. Al-Shuhaib, M.B.S. D76V, L161R, and C117S are the most pathogenic amino acid substitutions with several dangerous consequences on leptin structure, function, and stability. Egyptian Journal of Medical Human Genetics 2019, 20, https://doi.org/10.1186/s43042-019-0033-2.

32. Al-Shuhaib, M.B.S. The Deleterious F109S Mutation Disrupts Binding of Sex-Determining The Deleterious F109S Mutation Disrupts Binding of Sex-Determining Region Y with DNA. Karbala International Journal of Modern Science 2020, 6, 385-395, https://doi.org/10.33640/2405-609X.2082.

33. Al-Shuhaib, M.B.S.; Al-Shuhaib, J.M.B. Integrating state-of-the-art in silico tools with molecular docking to predict the impact of the most deleterious amino acid substitutions on TRAPPC6A protein. Current Science 2021, 120, 398-405, https://doi.org/10.18520/cs/v120/i2/398-405.

34. Dallakyan, S.; Olson, A.J. Small-molecule library screening by docking with PyRx. Methods in Molecular Biology 2015, 1263, 243-250. https://doi.org/10.1007/978-1-4939-2269-7_19.

35. Ashkenazy, H.; Abadi, S.; Martz, E.; Chay, O.; Mayrose, I.; Pupko, T.; Ben-Tal, N. ConSurf 2016: an improved methodology to estimate and visualize evolutionary conservation in macromolecules. Nucleic acids research 2016, 44, W344-W350, https://doi.org/10.1093/nar/gkw408.

36. Sagatova, A.A.; Keniya, M.V.; Wilson, R.K.; Sabherwal, M.; Tyndall, J.D.; Monk, B.C. Triazole resistance mediated by mutations of a conserved active site tyrosine in fungal lanosterol $14 \alpha$-demethylase. Scientific Reports 2016, 6, https://doi.org/10.1038/srep26213. 